\title{
Imaginário cartográfico na arte contemporânea sonhar o mapa nos dias de hoje
}

\author{
Gilles Tiberghien ${ }^{1}$
}

\section{Resumo}

O ensaio coloca várias interrogações sobre as relações entre arte e cartografia examinando procedimentos cartográficos em mapas de artistas contemporâneos. Ao investigar as regiões efêmeras e intersticiais nos mapas, o artista cartógrafo se interessa pela inadequação intrínseca à cartografia, dada pela impossibilidade de coincidência entre os mapas e seus objetos de representação. Seus mapas revelam o processo de fabricação imaginária próprio à cartografia em espaços usados e atuais. ${ }^{2}$

\section{Palavras-chave}

Mapas, cartografia, arte, representação, linhas, interstícios, imaginário cartográfico.

Recebido em 13 de Junho de 2013

Aprovado em 13 de Junho de 2013

TIBERGHIEN, Gilles. Imaginário cartográfico na arte contemporânea: sonhar o mapa nos dias de hoje. Trad. Inês de Araujo. Revista do Instituto de Estudos Brasileiros, Brasil, n. 57, p. 233-252, 2013.

DOI: http://dx.doi.org/10.11606/issn.2316-901X.v0i57p233-252

1 Universidade de Paris I Panthéon-Sorbonne (Paris, França).

2 Tradução Inês de Araujo e revisão técnica de Jaime Oliva. 


\section{Cartographic Imaginary in Contemporary Art Dreaming Maps Nowadays}

\section{Gilles Tiberghien}

\section{Abstract}

The essay raises several discussions about the relationship between art and cartography trough the analysis of cartographic procedures in maps made by contemporary artists. By investigating the ephemeral and interstitial regions in these maps, the cartography artist is interested in the inadequacy which is intrinsic to cartography, owing to the impossibility to make maps coincide with the objects they represent. Such maps reveal the imaginative process typical of cartography in its contemporaneous spaces.

\section{Keywords}

Maps, cartography, art, representation, lines, spaces, imaginary mapping. 


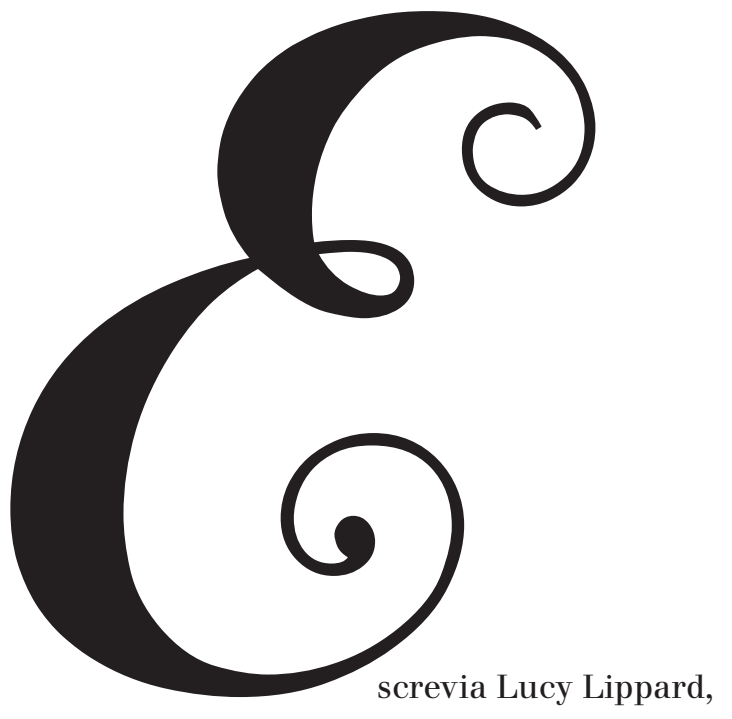

Premissa

"O mapa, assim como a arte que dele deriva,é em si fundamentalmente uma estratificação (overlay) - ele é simultaneamente um lugar, uma viagem e um conceito mental; abstrato e figurativo, distante e íntimo. Os mapas são como instantâneos de viagem, uma paralisação da imagem. A fascinação que experimentamos por eles deve ter relação com nossa necessidade de adquirir uma visão de conjunto, de situarmo-nos e de compreender onde estamos. $^{3}$

A arte e a cartografia estão ligadas há muito tempo, talvez desde as origens da cartografia. Os mapas medievais conhecidos como T em $O$ eram ricamente ornamentados, assim como os portulanos que aparecem desde o século XIII ${ }^{4}$. Para convencer-se de que os mapas são também obras de arte, basta consultar o "Atlas Catalão" de 1375, feito para Charles V, ou o "Atlas Miller" (cujo nome procede de seu último proprietário em 1519), feito por Lopo Homem. Os artistas foram recrutados para trabalhar em mapas, que, para serem produzidos, não dependiam de uma só pessoa, mas de uma cadeia de colaboradores: aquele que faz levantamentos, medindo as elevações e as superfícies dos terrenos, aquele que faz as coletas de dados, tais como, o inventário dos diferentes objetos, atividades, fluxos etc; aquele que

3 LIPPARD, Lucy. Overlay: contemporary art and the art of prehistory. Nova Iorque: Pantheon Books, 1983. p. 122.

4 Sua produção se estende do século XIII ao XVII. Ver o recente e rico catálogo-livro que acompanha a exposição da Biblioteca National de Paris, L'áge d'or des cartes marines. Quand l'Éurope découvrait le monde, direção de Catherine Hofmann, Hélène Richard e Emmanuelle Vagnon, Paris: Seuil/Bibliothèque Nationale, 2012. 
coteja e identifica os dados; aquele que transcreve os dados e lhes confere existência gráfica; aquele que grava e imprime os mapas etc.

Os artistas do renascimento participaram frequentemente da realização de mapas. Leonardo da Vinci (mapa de Imola 1502) foi introduzido na qualidade de cartógrafo a serviço dos Bórgia; Crivelli participou da realização de mapas (talvez da realização de certas gravuras da edição da Geografia - ou Cosmografia - de Ptolomeu realizada em Roma, em 1478). No século xvi, a cartografia se desenvolve nos Países Baixos, num meio onde se cruzam pensadores, humanistas e artistas. Abraham Ortelius foi não somente um livreiro/editor, um cartógrafo, autor do primeiro atlas moderno em 1570, mas também fazia iluminuras e era próximo de artistas como Brueghel e J. Hoefnagel ${ }^{5}$. Meu propósito aqui não é o de evocar as relações históricas entre cartógrafos e artistas ou entre arte e cartografia. Meu objeto diz respeito à arte contemporânea e suas relações com a atividade cartográfica, na medida em que o interesse pela cartografia desenvolveu-se muito no mundo da arte a partir dos anos 1960 (conjuntamente à chamada arte conceitual em sentido amplo) ${ }^{6}$, momento em que, em contrapartida, os geógrafos começaram a se interessar pelo que se passava na arte neste domínio.

Os artistas de fato reinterrogam os procedimentos próprios à cartografia. Eles acentuam problemas que os cartógrafos no exercício de seu trabalho acabam por não mais perceber, tamanha é a preocupação em produzir instrumentos confiáveis para localizar-se no espaço e avaliar as distâncias entre localidades designadas e nomeadas. Entretanto, os geógrafos, de uns trinta anos para cá, se interessam cada vez mais na atividade cartográfica, por aquilo que os anglo-saxões chamam de mapping, deslocando, em parte, suas análises mais para os processos que para os objetos.

Os artistas contemporâneos, por sua vez, mostram um interesse cada vez maior pelos mapas. Por um lado, considerou-se o mapa propriamente dito, em sua complexidade pictórica e semântica, não apenas pelo que designava (pode-se pensar, por exemplo, em Maps de Jasper Johns). De outro, mantendo igualmente o interesse pelo meio, certos artistas nos anos 1960, num momento de crise dos lugares tradicionalmente consagrados à arte, encontraram nos mapas uma forma de "documentar" ações efêmeras

5 BESSE, Jean-Marc. Le voyage, le témoignage, l'amitié. Abraham Ortelius \& George Hoefnagel en Italie (hiver 1577 - 1578). 2011.

6 É possível citar muitos livros ou catálogos de exposições sobre o tema, entre os quais, os recentes The Map on Art, Contemporary Artists explore Cartography de Katherine Harmon com textos de Gayle Clemens. Nova Iorque: Princeton Architectural Press, 2009; e MONSAINGEON, Guillaume. Mappamundi. Lisboa: Museu Berardo, 2011. 
ou de localizar realizações de difícil acesso que continuavam sendo objeto de especulações e manipulações bastante conceituais (pensemos nos artistas das chamadas land art ou environmental art dos anos 1960 e 1970).

Esse duplo interesse decorre da natureza complexa dos mapas que não estão inteiramente ao lado das imagens nem inteiramente ao lado dos conceitos, que são, se você preferir, espécies peculiares de imagens que procedem a um só tempo da representação concreta e do pensamento abstrato. O que pode, sem confundi-los entre si, identificar os mapas aos diagramas, quer dizer, à forma gráfica de uma síntese intelectual. Ou então, de outro modo, eles podem ser considerados como esquemas. Para ser mais completo, pode-se dizer, como o filósofo Nelson Goodman, que todo mapa é esquemático, seletivo e convencional. Retomarei brevemente esses três pontos:

\section{1) Esquemático}

A função do esquema é ser um intermediário entre o sensível e o inteligível e de reter ambos ao mesmo tempo. Se penso no número 5 e traço 5 pontos sobre uma folha, tenho uma imagem do número 5 . Trata-se de uma espécie de equivalente visual desse número. Mas se penso em 1000, traçar 1000 pontos me oferecerá desse número uma imagem confusa. Em contrapartida, quando digo 1000, o número me evoca muito claramente aquilo do que se trata. Pois bem, pode-se dizer como o filósofo Kant, a quem tomo emprestado esse exemplo, que o número 1000 corresponde a uma regra de construção a priori, a um método e que esse número é claramente inteligível como produto de uma síntese da minha imaginação. Do mesmo modo, o mapa é um operador desse mesmo gênero situado entre a imagem e o conceito. Trata-se de uma espécie de esquema.

\section{2) Seletivo}

Além disso, o mapa não mostra tudo: ele escolhe certo número de dados que quer mostrar em vez de outros. As florestas em vez das cidades, as estradas em vez das aglomerações, a agricultura em vez das indústrias etc. Quando há tudo isso ao mesmo tempo, a escala tem de ser bem pequena - como aquela do mapa-múndi - e a imprecisão torna-se muito grande. Quando há uma determinada escolha, a escala torna-se muito grande, e estamos diante de uma representação local ou corográfica, como, por vezes, esse tipo de representação é chamado. 


\section{3) Convencional}

O território é feito de objetos complexos. De natureza e de qualidades diferentes. O mapa tem por objeto colocar tais objetos sob o mesmo plano, torná-los comparáveis, mensurar e calcular as distâncias que os separam. Isso por meio de certos procedimentos: a rosa dos ventos, na época dos primeiros mapas do Mediterrâneo seguindo a linha dos ventos, ou o sistema de quadrículas que, desde o século XII, com Ptolomeu, permite situar as localidades designadas (tabelas ptolomaicas). No interior de um quadro normatizado, organiza-se a distribuição de nomes sobre a superfície branca em função desse enquadramento e de seus pontos de referência segundo as longitudes e as latitudes. Racionaliza-se, assim, o espaço.

Mas, para continuar com Goodman, podemos dizer com ele que:

O mapa não se contenta em resumir, clarificar ou sistematizar; ele revela fatos sobre os quais nós dificilmente tomaríamos conhecimento a partir de nossas explorações. Podemos fazer mapas mais vastos ou mais complicados ou mesmo modelos em três dimensões de modo a registrar mais informações; o resultado não é necessariamente bom. Pois, quando nossos mapas tornam-se muito grandes e em todos os pontos idênticos ao território cartografado - e, evidentemente, muito antes de se chegar lá -, os objetivos de um mapa deixam de ser alcançados. Não há nada que exista como um mapa completamente adequado, pois a inadequação é intrínseca à cartografia. $^{7}$

É desse afastamento que nos fala a arte contemporânea e é nesta inadequação que ela vai se instalar.

Tomaremos as coisas sob três ângulos: nomear; figurar; traçar.

\section{A. Nomear}

O mapa tem tudo a ver com a arte, pois retrata, escreve para descrever (literatura) ou permite fazer notações (música) - analogias entre mapas e partituras não faltam. Brian Harley enfatizou o caráter retórico dos mapas, que ele considerava também como "textos culturais", retendo, de leituras de Derrida e de Foucault, que os mapas têm um

7 GOODMAN, Nelson. Problems and Projects. Indianapolis: Hackett Publishing Co., 1972. p. 15 . 
estatuto metafórico inegável e que são a expressão do poder que refletem, mas que também fabricam.

Quando Harley escreveu que todos os mapas são retóricos, referia-se inclusive àqueles que se beneficiaram das técnicas mais avançadas, tanto que, dizia ele, "nós devemos desmontar o dualismo arbitrário entre a 'propaganda' e a 'verdade', entre os mundos da representação 'artística' e 'científica' encontrados nos mapas"8. Guiando-me por essa ideia, gostaria de examinar alguns exemplos de mapas artísticos que particularmente colocam em destaque esse aspecto. ${ }^{9}$

O belga de origem flamenga Win Delvoye fabricou com todos os detalhes um atlas imaginário contendo um planisfério físico, um planisfério político, 41 mapas e um índice de 2715 nomes ${ }^{10}$. "O atlas me permite ligar Jasper Johns e a land art”, escreve o artista, "mas também colocar em jogo a escritura: há muitas palavras e legendas em um mapa. Eu invento palavras e passo muito tempo verificando que elas realmente não existem..."11. Tal qual Tolkien criava nomes de povos e regiões imaginárias com base em raízes linguísticas variadas, como finlandesas e semíticas, nos mapas da Terra do Meio, Win Delvoye forja nomes com sonoridades próximas a topônimos conhecidos ou remetendo a uma nomenclatura estabelecida. Logo, encontramos "Gulf" ou "Golfe", "Bay" ou "Baai”, "Archipel”, Öchypels" ou "Pelago", "channel”, "détroit", "Island" para descrever o relevo complexo das áreas litorâneas e o modo como as terras e a água se interpenetram. Os nomes são as vezes evocadores de formas que subitamente se impõem, revelando-nos tal animal ou tal objeto maliciosamente introduzido nos contornos de um continente ou no desenho de uma ilha. Desse modo, sobre a prancha Carte $\mathrm{n}^{0} 3$, Cihatailoi Nord ${ }^{12}$, à quase ilha de New-Hamma atribui-se o perfil de um martelo colado a um sino chamado Soana, cuja capital é Dogful ao sul de New-Caril. De prumo, no lugar do batente, encontra-se um pequeno arquipélago chamado Islas Carrilens.

8 HARLEY, Brian J. Le pouvoir des cartes. Seleção de textos por Peter Gould e Antoine Bailly. Paris: Anthropos, 2003. p. 94-95.

9 [N.E.] Todos os esforços foram feitos pelo autor e pelos editores para que este artigo pudesse trazer as ilustrações dos mapas citados. Contudo, por conta dos direitos autorais ou pela qualidade de imagens obtidas, optou-se por informar, quando possível, os sítios da internet nos quais as imagens podem ser consultadas livremente.

10 DELVOYE, Wim. Atlas. Michel Baverey. Pays de Loire: Frac, 1999.

1 DELVOYE, Wim em GNS - Global Navigation System. Paris: Palais de Tokyo; Éditions cercle d'art, 2003. p. 94-95.

12 Disponível em: http://desordem.tumblr.com/post/2925700162/breviario-de-grandes-imaginacoes-wim-delvoye. Acesso em: set. 2013. 
Marcel Broodthaers chegou oficialmente muito tarde à arte. Somente passados os quarenta anos de idade, ele realizou suas primeiras obras nas artes plásticas. Sua prática de poesia levou-o, naturalmente, a interrogar-se quanto ao sentido dado às palavras. A tentativa mallarmeana de um Coup de dés encontra em sua obra, Un coup de dés jamais n'abolira le hasard (1969), subtítulo "Image", sua forma radical de erradicação da palavra em favor de sua "obstrução" espacial traduzida geometricamente por barras negras da mesma altura que as letras mais altas e da mesma largura que as frases do texto. Essa técnica, que oblitera os sentidos em favor do efeito plástico, especulando sobre o ritmo e a posição das linhas assim obtidas, foi retomada pelo artista italiano Emilio Isgrò, que realizou, em 1970 e ainda alguns anos mais tarde, uma série de obras que consistiam em obscurecer todos os topônimos de mapas das geografias da Itália, do Mar Mediterrâneo ou das Caraíbas, renomeando esses mapas com os títulos do mapa de origem - por exemplo, Mar dei Caraibi 1970 - e dando a todos a legenda: Carta geografica cancellata ${ }^{13}$.

Compreende-se a tentação dos artistas em trabalhar sobre os mapas numa perspectiva comparável. Citei a obra de Emilio Isgrò, mas poderia tomar dois exemplos em certo sentido opostos entre si: o de David Renaud e o dos artistas Anne-Marie Jugnet e Alain Clairet. O primeiro para mencionar apenas um aspecto de seu trabalho - pintando sobre um mapa intitulado Giverny, o esvazia de todos os signos, formas ou cores, com exceção dos nomes da região que aí encontravam-se inscritos, obtendo assim uma espécie de caligrama, sem que se perceba muito bem qual é o sistema de arranjos que lhe daria sentido. Estamos assim diante de um "mapa - poema, que, pela litania de seus topônimos sugere ou sublinha as convenções que constroem toda paisagem. E também uma evocação proustiana da potencia poética da onomástica face à extrema fragilidade de nossas memorias visuais"14.

De modo oposto, Anne Marie Jugnet e Alain Clairet trabalham sobre plantas de cidades da América do Norte situadas na periferia dos desertos americanos do Oeste. O que eles perceberam, consultando essas plantas, é que algumas "representam apenas o vazio", um vazio, sem dúvida, destinado a ser preenchido e que antecipava os processos de urbanização, mas que também pode, não menos, ser uma espécie

13 Ver BONITO OLIVA, Achille. Emilio Isgrò, compreste questa virola da Emilio Isgrò. Milão: Mazzotta, 2000.

14. JOUANNAIS, Jean Yves. David Renaud: "De la cartographie comme cartomancie". Montreuil: Éditons de l'œil, 2009, p. 10. Ver também RENAUD, David. Atlas, IIg jours autour du monde. Paris: Le temps qu'il fait, 2006. 
de cartografia dos possíveis. A operação artística consistiu então em suprimir os nomes das ruas "quer dizer, a linguagem propriamente". Opondo-se, portanto, a David Renaud, sobre esse ponto, eles consideram que permanecer na linguagem teria sido "entrar numa poética de palavras. Pareceu-nos essencial", acrescentam, "aceder diretamente à estrutura do território" ${ }^{15}$.

\section{B. Figurar}

Para imaginar é preciso que haja distância entre si e o mundo, é preciso o vazio entre as coisas, o nada no interior do ser. O mapa, em seu processo de fabricação imaginária, tem alguma coisa a ver com esse vazio, como bem souberam observar e traduzir certos artistas tentando cartografar esse "entre", ou esse branco, esse interstício. Foi o que fizeram, por exemplo, Terry Atkinson e Michael Baldwin com o mapa representando dois estados dos Estados Unidos, Iowa e Kentucky ${ }^{16}$ isolados em um quadro branco do resto do país. Uma lista que se pode ver ao lado enumera os outros estados ausentes. O mapa situa-se assim nesses "entrefiguras" ou nesse jogo de figuras (cheias) e de fundo (vazio), mesmo fazendo referência à enumeração de topônimos que obedecem a outro regime de signos, suscetíveis em direito de completar o mapa, mas incomensuráveis, de fato, aos vazios que eles supostamente devem preencher.

Isso nos remete às manchas brancas das antigas cartografias que ainda são encontradas no século XIX, que recordavam as zonas inexploradas, esses espaços brancos dos quais nos fala Marlow, o narrador do No coração das trevas ${ }^{17}$.

Certamente a cartografia pode aumentar ou alargar o território a partir de sua imagem ou de sua forma mental. É o que se empenha em

15 JUGNET, Anne Marie; CLAIRET, Alain. Extraits de conversations, 13 novembre 1999. Séries americaines. Sotteville-Les-Rouen: Trafic Frac Haute-Normandie, 2000 .

16 Disponível em: https://www.tate.org.uk/art/artworks/art--language-terry-atkinsonborn-1939-michael-baldwin-born-1945-map-to-not-indicate-po1357. Acesso em: set. 2013 .

17 "Quando eu era criança”, confidencia o personagem imaginado por Conrad, "eu tinha paixão por mapas. Ficava horas considerando a América do Sul, ou a África, ou a Austrália - perdido em todas as glórias da exploração. Nesta época, havia muitos espaços brancos sobre a terra, e quando percebia um deles sobre o mapa, que tivesse um ar particularmente atraente, (mas eles todos têm esse ar) colocava o dedo em cima e dizia: 'Quando eu for grande irei lá...'”. CONRAD, Joseph. Au cœur des ténèbres. Paris: Gallimard, 2oog. p. 89-9o. 
fazer o grupo Stalker, que por meio de suas caminhadas e deambulações nas cidades, tenta revelar outra cidade sob a cidade. Trata-se de uma abordagem de descoberta e de exumação, de invenção. Os mapas que resultam dessas investigações - o de Roma identificada a um arquipélago é o mais conhecido. Eles são exatamente o que Deleuze e Guattari entendem por "performance" quando opõem mapa e decalque e escrevem que "o mapa é uma questão de 'performance', enquanto o decalque remete sempre a uma “competência' pretendida"18. Ora, esse mapa também é feito para se perder ou para perder nossas relações habituais com o mundo, fazendo aparecer territórios intersticiais, nomeados territórios atuais, em azul como o mar, enquanto a cidade repertoriada e densa está em amarelo e parece um arquipélago ${ }^{19}$. Mas essas zonas são fluidas e móveis; e o mapa, aquático. Obtém-se assim "um conjunto de ilhas”, contínuo que penetra nos espaços plenos e se ramifica em diversas escalas até os menores interstícios abandonados entre as porções de cidade construída.

Desse parêntese espacial Robert Smithson oferece uma imagem muito forte com o mapa de Mono Lake ${ }^{20}$. Em 1968, Smithson, Nancy Holt e Michael Heizer partem em viagem para o Oeste e são hospedados na casa dos pais de Michael em Lake Tahoe. Mono Lake é um antigo lago salgado, agora seco, situado não longe dali. Smithson ficou fascinado pelo tipo de paisagem que via, uma paisagem que pode ser qualificada como recessiva. Em seu retorno ele recorta o mapa de Mono Lake mantendo apenas uma fina borda com a qual constrói um receptáculo de forma correspondente, que preenche com os materiais dos depósitos vulcânicos do próprio lugar, como pedras-pomes e cinzas frias. O mapa é a réplica daquele de Lewis Carroll no começo de A caça ao Snark, um mapa no qual só vemos o mar: "Agradeçamos nosso bom capitão/ exclama a tripulação, trata-se do melhor mapa o que ele nos oferece/ Um vazio perfeito e absoluto"21.

O que imediatamente chama atenção nesse não lugar é o vazio, como se o lugar propriamente dito se encontrasse rejeitado após as bordas. Smithson o diz muito bem, o mapa tem "a forma de uma borda - que não tem centro. Na realidade é apenas um enquadramento" ${ }^{22}$. Ele dizia que o lugar parecia submetido a um irresistível movimento

18 DELEUZE, Gilles; GUATTARI, Felix. Mille plateaux. Paris: Minuit, 1980. p. 20.

19 Ver CARERI, Francesco. Walkscape. Rome: Einaudi, 2006.

20 Disponível em: http://pmc.iath.virginia.edu/issue.105/15.2altieri.html. Acesso em: set. 2013 .

21 CARROLL, Lewis. La chasse au Snark. Trad. fr. Jacques Roubaud. Paris: Ramsay, 1986. p. 16.

22 SMITHSON, Robert. The Collected Writings. Org. Jack Flam. Berkeley: University of California Press, 1996. 
de evaporação e que quanto mais se aproximava dele, mais parecia se evaporar. Descrevendo Mono Lake, repensava sobre sua dialética do lugar e do não lugar: "o que há de interessante no não lugar", continua ele,

é que, à diferença do lugar, ele nos conduz em direção às bordas. Em outros termos, não há nada sobre o que se apoiar a não ser as cinzas e não há nenhum meio de parar sobre um ponto particular. Poderíamos dizer que o lugar se evaporou ou desapareceu. É um mapa que os levará a algum lugar mas quando vocês aí chegarem não saberão exatamente onde estão. Em certo sentido, o não lugar é o centro do sistema, e o lugar, ele próprio, o limite ou a borda. ${ }^{23}$

Esse descentramento é um modo de situar-se voluntariamente nas fronteiras dos mundos conhecidos, como nos mapas da Antiguidade e suas Terrae incognitae, deixando livre curso às especulações. Mas a diferença aqui é que, desde Galileu e Copérnico, sabemos que a Terra não está mais no centro do Sistema Solar e que estaremos sempre destinados às margens, às bordas de mundos desconhecidos que nos circundam $\mathrm{e}$ que tentamos explorar. Por tudo isso, a representação de nosso mundo seguindo uma perspectiva centrada torna-se ingênua e irrisória.

\section{Traçar}

Por fim, gostaria de considerar o mapa sob o ângulo do traçado, no sentido do deslocamento e da impressão que este deixa na memória, no sentido também do trajeto que permite ou de que trata; enfim, do tipo de intensidade que traduz indicando não somente quantidades, mas também qualidades.

\section{a) Mapas e memória}

Graças a essa disposição particular de nosso corpo podemos fazer para nós mesmos certa representação do mundo e nos imaginar fazendo parte dele. Sem nosso corpo com seus dois lados, nenhum ponto no cosmos seria apreensível, nenhuma leitura de mapa seria possível. Para nossa orientação, em geral, dispomos o mapa sempre à nossa frente em relação à nossa direita e à nossa esquerda. O episódio de Carlitos no clássico Em

23 Idem, ibidem. 
busca do ouro, no qual o "pequeno homem" tenta se orientar fixando diante dele um mapa como se fosse uma direção absoluta e girando em volta, é bastante sugestivo desse ponto de vista.

Os professores de geografia conhecem bem o exercício que consiste em fazer seus estudantes desenharem de memória o mapa de um país estudado. Certos sociólogos se empenham em fazer desenhar o mapa de uma região por seus habitantes para melhor compreender que representação dela eles têm. O Kir Dingle, United Shapes of America - mapa dos Estados Unidos desenhado por adolescentes -, de 1991, é bastante eloquente desse ponto de vista ${ }^{24}$. A despeito de nossa maior ou menor habilidade para desenhar, nem sempre temos uma ideia justa das proporções ou das relações entre os diferentes espaços que nos são familiares, pois situamos mal uns em relação aos outros ${ }^{25}$. Os fatores de deformação são múltiplos e dependem sem dúvida da psicologia de cada um, mas, em geral, projetamos sobre o mundo um conjunto compósito de formas coloridas por nossos afetos e extraídas de nossa memória, que sobrepõe à paisagem real uma paisagem mental. Os mapas, assim realizados, manifestam contornos instáveis.

Além disso, trata-se às vezes de imagens coletivas, como se vê nas variações de Fabro sobre a "bota" italiana" ${ }^{26}$.

Alguns artistas colocam deliberadamente esses processos em evidência para manifestar a maneira como, por mais familiar que sejam para nós as plantas, os mapas ou diagramas de um espaço que nós percorremos frequentemente, a memória que deles guardamos permanece sempre numa relação distanciada do real, sendo essa relação sempre sujeita às variações do nosso imaginário topográfico, o qual, por sua vez, depende da atualização de nosso corpo no espaço. Assim o artista Pierre Joseph, quando reconstitui o mapa do metrô parisiense de memória ${ }^{27}$, reutilizando os códigos gráficos da RATP, afirma, ao mesmo tempo, por meio das lacunas que nós descobrimos após um exame atento, a singularidade de seus usos. "Eu acredito nas representações coletivas,

24. Esse mapa está reproduzido em HARMON, Katharin. You are here. Personnal Geographies and other Maps of Imagination. Nova Iorque: Princeton Architectural Press, 2004. p. 110.

25 Ver DE CERTEAU, Michel. L'invention du quotidian, I. Paris: Gallimard, 199o. Capítulo X, p. 170.

26 Existem umas trinta com títulos variados, "Italia d'oro", "it-alia”, "italia dei pupi", "italia elastic", "Cosa nostra", "Italia poco seria" etc.

27 Disponível em: http://www.radicalcartography.net/index.html?pierre-metro. Acesso em: set. 2013 . 
universais, e as busco nesse jogo, e tento me aproximar delas o máximo, mas eu existo no hiato que me separa desses modelos"28.

$\mathrm{Na}$ categoria das cartas mnemônicas, vale lembrar a experiência tentada pelo artista Stanley Brouwn, que, em 1960, em Amsterdã, pedia aos transeuntes para lhe indicar seu caminho por meio de croquis e esquemas desenhados em pequenos pedaços de papel. Os croquis, a despeito de suas qualidades gráficas, foram conservados e gravados com o nome de This Way Brouwn. Nenhum desenho é melhor que outro, e nenhum sobre o conjunto foi selecionado ou modificado.

Resulta dessa experiência um conjunto de traços que comportam, ao mesmo tempo, o dito e o não dito, o que é supostamente conhecido sem ser identificado pelo interlocutor, o que ele apreende sem que o desenho o mostre etc. "As pessoas falam fazendo croquis", explica Brouwn, "e por vezes falam mais do que desenham. Sobre os croquis, pode-se ver o que as pessoas explicam. Mas não se pode ver o que elas omitem tendo alguma dificuldade em realizar o que para elas parece evidente e não precisa ser explicado" 29 . Aqui nos encontramos em uma representação infracartográfica, mas que subentende toda representação espacial. Percebe-se que os diagramas valem tanto quanto, ou mais, pelo que omitem do que pelo que mostram.

O espaço descrito é tipicamente um espaço hodológico ou existencial, do qual cada transeunte produz uma figuração diagramática em função da maneira como seu corpo é afetado pela lembrança da ação: essa lembrança toma uma forma gestual e gráfica. Isso corresponde muito bem às conclusões que Merleau-Ponty pode extrair das análises de Köhler sobre a inteligência dos macacos superiores por analogia com nosso comportamento no espaço:

As atitudes motoras não são um substituto para os dados visuais. Os gestos de orientação não têm significado, nesse caso, quanto ao trajeto do qual formamos algumas representações visuais. $\mathrm{O}$ que a atitude motora fornece não são conteúdos, mas sim o poder de organizar o espetáculo visual, de traçar entre os pontos do espaço representado, as relações das quais temos necessidade. Esse recurso atribuído aos dados táteis é em realidade um recurso do espaço vivido, em oposição ao espaço virtual, no qual nossas indicações situavam-se primeiramente [...]. A dificuldade de uma

28 Pierre Joseph em GNS - Global Navigation System. Org. Franz Ackermann. Paris: Cercle d'art, 2003. p. 124.

29 This way Brouwn, 25 - 2 - 6I. 26 - 2 - 6I. König Köln; Nova Iorque: Verlag Gebr., 1961. 
descrição pura do itinerário é da mesma ordem que aquela de ler um mapa ou de se orientar por meio de uma planta [...]." ${ }^{30}$

\section{Mapas de trajetos}

Desde a Antiguidade encontramos mapas produzidos graças aos serviços de informação e de viagem que recolhiam dados permitindo aos viajantes guiar-se com mais segurança. Essas tabulae se apresentavam sob a forma de rolos que eram desenrolados aos poucos durante 0 percurso. Eram desse gênero os mapas de peregrinações para ir a Jerusalém, a Roma ou então - bem mais tarde, ao que parece - a Meca. As estradas romanas calculadas com precisão permitiram desde a Antiguidade a existência desses guias. Aí se encontrava a indicação de cidades, de casas onde dormir à noite (mansiones), de paradas para a troca de cavalos (mutationes). O Itinerarium Antonini, datado da época de Diocleciano, é uma importante compilação de itinerários percorrendo o Império, no qual as distâncias são indicadas em “milhas romanas". O mapa Pautinger - nome de seu último proprietário, Konrad Pautinger (1465 - 1547) - data da época de Constantino (século IV) e oferece indicações detalhadas e uma representação das estradas e de suas conexões ao longo de 100 mil quilômetros. Os caminhos partiam de Roma a leste e a oeste, e suas ramificações eram limitadas pela largura do pergaminho desenrolado, em cujas bordas se representavam os mares como finas faixas de água. Na Inglaterra do século XIII, os mapas foram desenhados para viagens que partiam sempre do sul, sendo este disposto no alto do mapa, com indicações sobre os territórios, inseridas nas margens que excediam o quadro da imagem cartográfica. Encontramos também, mais tarde, no século XVII mapas de caminhadas como o de Ogylvie que devia ser desenrolado diante de si. O interessante é que Ogylvie tinha sido dançarino e depois do incêndio de seu teatro, no fim da vida, empreendeu a edição desses guias de caminhada.

São justamente essas mesmas operações colocadas em evidência pelos artistas caminhantes no uso que fazem dos mapas hoje em dia. Para Richard Long, que há cerca de quarenta anos caminha pelo mundo deslocando pedras, que ele alinha ou que ele ergue segundo formas geométricas simples, o mapa funciona como um sistema de equivalência, permitindo "fixar" fotografias de paisagens que ele atravessa, no interior

3o MERLEAU-PONTY, Maurice. La structure du comportement. Paris: PUF, 201z. p. 127-128. 
de um sistema de coordenadas ${ }^{31}$. Os nomes que figuram nos mapas nos informam sobre o tempo necessário para percorrer a distância indicada ou sobre a forma de um percurso. Podemos ler nelas uma ou muitas datas, uma localização etc. Low Water Circle Walk traz como subtítulo " $A$ 2 days walk around and inside a circle in highland Scotland Summer". O círculo traçado sobre o mapa é a um só tempo abstrato e concreto: sua forma geométrica faz pensar na ideia de uma caminhada, mas cada vez que o traçado encontra a água, de um rio ou de um lago, este se molda ao relevo, à forma de uma margem e faz ver a geografia sob a geometria, a paisagem sob o mapa.

Por vezes é dito, como em Dartmoor Riverbeds, que essa caminhada foi feita no interior de um perímetro circular puramente mental no leito de um ou de muitos rios, cujo traçado é assim sublinhado sobre o mapa; as fotografias de cada um desses rios são dispostas, face a face. Pode acontecer também de o mapa não indicar mais uma caminhada, mas o tempo de uma pausa como em Twelve Hours Twelve Summits, no qual, sobre cada cume atingido durante uma caminhada de cinco dias nas Highlands, uma placa é colocada com a seguinte inscrição: "one hour". Long insiste em seus textos e entrevistas sobre o sistema de rastros que ele compõe na superfície da Terra, tanto o seu como o de outros caminhantes, de homens e animais em geral. "Uma caminhada não é senão uma camada a mais, uma marca depositada na superfície do terreno, sobre as milhares de outras camadas de história humana e geográfica. Os mapas ajudam a mostrá-lo" ${ }^{2}$.

\section{Linhas de intensidade e ritmos}

As linhas de construção em matéria de cartografia concernem primeiro e, sobretudo, às formas e às quantidades: as fronteiras, os limites territoriais, o desenho das redes viárias, os traçados orográficos, a localização das cidades. Mas igualmente à quantidade de parcelas de terra cultivadas ou em repouso, a extensão das zonas residenciais, os estacionamentos e o número de carros que eles podem conter etc.

Pode-se também considerar as linhas cartográficas como linhas de força que não indicam somente as quantidades, mas também as qualidades e as intensidades. É, em todo caso, desse ponto de vista que geralmente os artistas se interessam pelos mapas. Ora, existem mapas

31 Disponível em: http://www.richardlong.org/Documentations/text/index.html. Item 29 da Textworks Gallery. Acesso em: set. 2013.

32 Ver Richard Long em LIPPARD, Lucy. Overlay. Op. cit., p. 129. 
desse gênero que encontramos entre os esquimós, mas também nas ilhas Marshall (Figura 1) onde, representada em uma estrutura reticular, a concha que se encontra no centro de um feixe de galhos representa a ilha do "cartógrafo", e os galhos representam os movimentos de convergência e divergência das águas. Esses mapas não são embarcados; são consultados e memorizados em terra pelos navegadores.

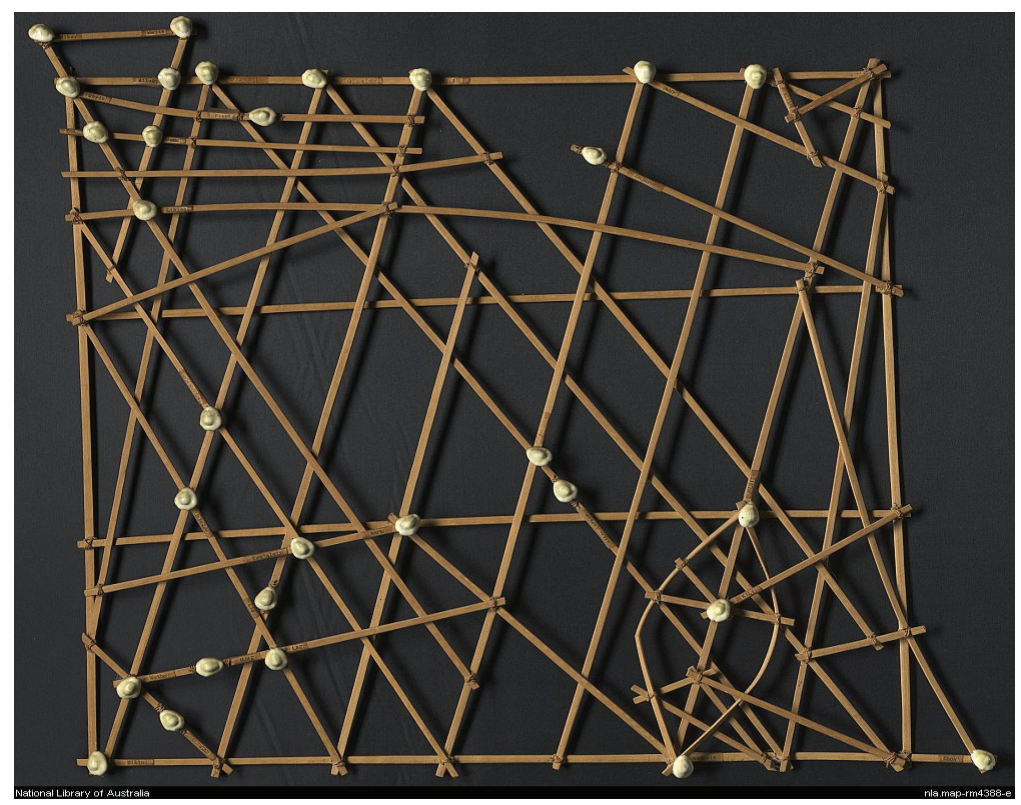

Figura 1: Carta Marinha das Ilhas Marshall.

Há duas maneiras de se servir deles.

A primeira se apoia sobre dois tipos de referência: primeiro a direção do vento que vem constantemente do norte, em seguida a posição das estrelas (a Polar e o Cruzeiro do Sul). A isso se deve acrescentar o sentido das migrações dos pássaros e uma curiosa medida do tempo, "a repetição de um mesmo canto ao longo de todo trajeto", que nos leva irresistivelmente a pensar nas Song Lines, nos "cantos dos rastros", descritos por Bruce Chatwin, que delimitam superfícies territoriais. Mas se poderia dizer como Merleau-Ponty a propósito de Uexküll e de seu modo de conceber o Umwelt, que se trata propriamente de alguma coisa que se canta por intermédio da voz de cantores mais do que do que eles 
próprios cantam, como se eles fossem atravessados por esse canto, de tal modo que suas entonações tornam-se como coordenadas cartográficas ${ }^{33}$.

A segunda maneira de considerar esses mapas é de nele decifrar o movimento do mar cristalizado, de algum modo. As varetas de madeira, em geral, representam as dobras das ondas, formadas pela ressaca de outras ondas. Assim Georges Kish, que estudou esses mapas, descreve as realidades da qual eles tratam: "Quando uma onda se aproxima da costa, sua crista torna-se deformada e refrata o perfil da beira do mar, sob a ação dupla do freio das águas interrompidas e do contra movimento das ondas devolvidas (em reflexo)". Logo,

o que representam as varetas do modelo são precisamente as linhas ao longo das quais se podem ver as cristas das ondas mudarem de orientação quando se distanciam de uma ilha: refração da forte corrente leste, aquém da ilha, seguindo as duas ramificações, Norte e Sul: mesmo fenômeno para a frágil corrente oeste, além da ilha $[\ldots] .^{34}$

Trata-se aqui de uma rede dobrada à qual corresponde o mapa. Robert Smithson com Untitled [Folded Map of Beaufort] ${ }^{35}$, ilustra esse modo de considerar o mundo como uma "realidade dobrada", por meio dos mapas dos quais nos servimos. De fato, para ler os mapas hoje em dia, nós os desdobramos, e este hábito nos oferece, ao mesmo tempo, uma visão dessa "realidade dobrada" que é o espaço representado. Podemos lembrar, nesse sentido, a observação de Notes sur le cinématografe, de Robert Bresson, citando um general que dizia: "As grandes batalhas [...] acontecem quase sempre nos pontos de interseção dos mapas do estado-maior" 36 .

Mas o tempo é também o desdobramento ou a extensão da dobra cujo instante é expressão e cuja tradução espacial pode ser encontrada em Oppenheim, em sua obra Time Pocket, realizada em $1968^{37}$. O artista escavou na neve de um lago gelado, perto do Fort Kent, na fronteira canadense, uma vala que materializa a linha de mudança de data, como também de dia.

33 MERLEAU PONTY, Maurice. La nature, notes: "traces écrites". Paris: Seuil: 1994. p. 228.

34 KISH, Georges. La carte. Image des civilisations. Paris: Seuil, 1980. p.9 188.

35 Disponível em: http://www.robertsmithson.com/ex_events/folded_map_of_beaufort.htm. Acesso em: set. 2013 .

36 BRESSON, Robert. Notes sur le cinématographe. Paris: Gallimard; Folio, 1995. p. zo.

37 Disponível em: http://stephan.barron.free.fr/technoromantisme/oppenheim.html. Acesso em: set. 2013 . 
Se de um lado dessa linha, o lado canadense, são 11h10, do outro, do lado dos Estados Unidos, são 10h10, por exemplo. Esse traçado, ao longo de uma milha, é interrompido por uma ilha situada no meio do lago e se estende do outro lado por mais meia milha. Oppenheim intitula essa intervenção Time Pocket.

Ela obedece ao mesmo princípio que a Time Line, que joga com as convenções dos fusos horários, salvo que aqui "o bolso do tempo" dobra e redobra que precisamente é a forma como se faz bolsos a partir de um tecido - corresponde a um vazio intersticial, um instante concebido como limite interno do tempo, para retomar uma concepção tomada emprestada da Física de Aristóteles.

Diferentemente do cartógrafo, o artista não se interessa pela medida em si, mas empenha-se, ao contrário, em confundi-las. Esse ato de confundir pode ser dinâmico e pode-se pensar o mapa como um diagrama que desenha multiplicidades espaço-temporais, de tal modo que o mapa se torna um traçado de relações de força, um sismógrafo de intensidades, a figuração de coisas efêmeras e quase inapreensíveis. Um mapa da artista brasileira Anna Bella Geiger, Mapa mundi com ventos I (Figura 2), representa os ventos que atravessam a América do Sul, isolada sobre o mar, e que parecem manter todo o continente em suspenso, como parênteses no meio do mundo.

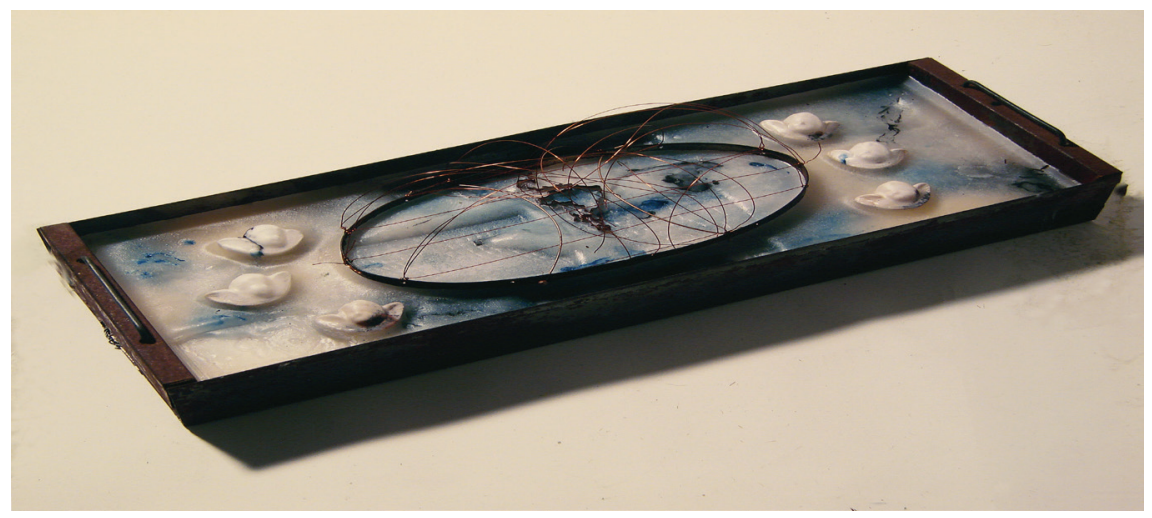

Figura 2: Anna Bella Geiger, Mapa mundi com ventos I, 1995, $20 \times 59 \times 10 \mathrm{~cm}$.

O artista-cartógrafo projeta assim um novo atlas que mantém, como se levada por correntes aéreas, a única massa de terra que ele elegeu e que o representa daqui pra frente. O imaginário que esse mapa 
testemunha não nos afasta do real, mas nos faz penetrar na visão de um artista, em sua maneira de ver e sentir, no movimento dinâmico de seus afetos, que nos restitui a imagem como a franja de um sonho. Assim como nos mapas que consultamos deixando errar nosso espírito (e que os artistas sabem guiar até regiões insuspeitas), entre duas folhas de um atlas em que não há, à primeira vista, nada a ser visto.

\section{Sobre o autor:}

\section{Gilles Tiberghien}

Professor de Estética na Universidade de Paris I - Panthéon-Sorbonne. Filósofo e ensaísta, publicou, entre outros, Pour une république des rêves (Les presses du réel, 2011) e Aimer une histoire sans fin (Flammarion, 2013).

E-mail: gillestiberghien@noos.fr 
